\title{
Nonopioid versus Opioid Based General Anesthesia Technique for Laparoscopic Cholecystectomy
}

\author{
Mostafa Shalaby, Mofeed Abdalla, Amr Samir Mahmoud \\ Department of Anesthesiology, Intensive Care and Pain Management, Faculty of Medicine, Al-Azhar \\ University, Cairo, Egypt \\ Corresponding author: Amr Samir Mahmoud, Mobile: 01061981288; Email: moori.more@gmail.com
}

\begin{abstract}
Background: The choices of premedication and anesthetic techniques are able to influence the neurohormonal stress response by modulating the pathophysiological pathways. Various pharmacological agents like nitroglycerine, beta blocker, and opioids were used to decrease surgical stress of laparoscopic procedures to improve outcome, with their own limitations.

Objective: It was to compare the effect of opioid-free (using dexmedetomidine and propofol) and opioid-based (using fentanyl and propofol) TIVA techniques on hemodynamic stability, sedation postoperative pain intensity and the incidence of side effects in patients scheduled for LC.

Patients and Methods: Eighty patients who were scheduled for elective laparoscopic cholecystectomy were included in this study. Before induction of anesthesia, patients were randomly divided into two equal groups: (40 each). Dexmedetomidine group (Non-opioid group) received dexmedetomidine $(1 \mu \mathrm{g} / \mathrm{kg})$ over 10 minutes before induction of anesthesia followed by continuous infusion of $0.5 \mu \mathrm{g} / \mathrm{kg} / \mathrm{hr}$. till the end of surgery and Fentanyl group (Opioid group) received fentanyl $(1.0 \mu \mathrm{g} / \mathrm{kg})$ over 10 minutes before induction of anesthesia followed by continuous infusion of 0.4 $\mu \mathrm{g} / \mathrm{kg} / \mathrm{hr}$. till the end of surgery.

Results: The results of the present study showed that there were no significant differences between the two groups regarding HR and MAP except after loading dose of the studied drugs, after intubation, after pneumoperitoneum, $15 \mathrm{~min}, 30 \mathrm{~min}, 45 \mathrm{~min}$, and $60 \mathrm{~min}$ after induction where it was lower in dexmedetomidine group than fentanyl group. There were no significant differences between two groups regarding intraoperative SPO2, postoperative SPO2 and blood glucose level (mg/dl).

Conclusion: This study concluded that dexmedetomidine is better than fentanyl for patients who undergo elective laparoscopic cholecystectomy due to perioperative maintaining of hemodynamic stability, decrease dosages of postoperative analgesics, prolong the duration of postoperative analgesia and decrease postoperative nausea and vomiting.
\end{abstract}

Keywords: Pure laparoscopic surgery, open surgery

\section{INTRODUCTION}

Pure laparoscopic surgery (PLS) has been adopted in various fields. Compared with open surgery (OS), PLS has substantial advantages in terms of less blood loss, less pain, a lower morbidity rate, a shorter time to a postoperative diet, and a shorter hospital stay (I).

Laparoscopic surgery has a different pain profile than normal open surgery. Pain during laparoscopic surgery is a result of both somatic and visceral afferents ${ }^{(2)}$.

Somatic and visceral pain can be distinguished by the quality of the pain and associated clinical features ${ }^{(3)}$.

Somatic pain: results from excitation and sensitization of nociceptors in tissues such as bone, periarticular soft tissue, joints, and muscles. Four physiologic processes are involved in the somatic nociception: transduction, transmission, modulation and perception. Somatic pain is characterized as being well localized topographically, intermittent or constant and is described as aching, stabbing, or throbbing ${ }^{(4)}$.

Visceral pain: it is not evoked from all visceral organs, such as liver, kidney. Most solid viscera and lung parenchyma are not sensitive to pain. It is not always linked to visceral injury (cutting the intestine causes no pain, whereas stretching of the bladder causes pain). It is diffuse and poorly localized. It is referred to other locations. It is accompanied by motor and autonomic reflexes, such as nausea and vomiting. It is often described as dull, colicky, or squeezing ${ }^{(5)}$.

The use of opioids can add to the side effect profile of patients undergoing robotic 
and laparoscopic surgery by further aggravating PONV and ileus and causing prolonged sedation. Large bolus doses of opioids intraoperatively can also lead to postoperative hyperalgesia and increased consumption of rescue analgesics ${ }^{(6)}$.

The use of opioid sparing and opioidfree analgesic techniques have the propensity to decrease and even avoid many of these side effects and lead to early oral intake, early ambulation, earlier hospital discharge, and lesser readmission rates to the hospital in the postoperative period $^{(7)}$.

Multimodal analgesic techniques such as use of acetaminophen, pregabalin, cyclooxygenase-II inhibitors, nonsteroidal anti-inflammatory drugs, local anesthetics, beta-blockers, dexamethasone either alone or in combination, have been shown to decrease the requirement of opioids intraoperatively and postoperatively. However, none of these drugs are effective as the sole analgesic, and thus the need for evaluating newer drugs as replacement of opioids in the intraoperative period is still continuing. Alpha-2 agonists such as clonidine and dexmedetomidine have shown promising results in this context ${ }^{(7)}$.

The aim of this work was to compare the effect of opioid-free (using dexmedetomidine and propofol) and opioidbased (using fentanyl and propofol) TIVA techniques on hemodynamic stability, sedation postoperative pain intensity and the incidence of side effects in patients scheduled for LC.

\section{PATIENTS AND METHODS}

This study included a total of eighty patients who were scheduled for elective laparoscopic cholecystectomy attending at AlAzhar University Hospitals. Approval of the ethical committee and a written informed consent from all the subjects were obtained. This study was conducted between November 2017, and July 2018.

Inclusion criteria included: Age group of 20-60 years, of both sexes and ASA physical status I and II.

Exclusion criteria: Patients refusal, body mass index $>35 \mathrm{~kg} \mathrm{~m}^{-2}$, pregnant, lactating and menstruating women, hepatic, renal and cardiac insufficiency, DM, history of chronic pain, alcohol or drug abuse, psychiatric disease, allergy, contraindication to any of the study drugs, inability to assess pain or to use a patient-controlled analgesia (PCA) device.
Patients were fasted for 8 hours with opportunity to drink clear fluid up to 2 hours before the operation.

Patients passing inclusion criteria were further evaluated by medical history, physical examination and laboratory investigations; complete blood picture "CBC", renal function tests, liver function tests, prothrombin time (PT \& INR), partial thromboplastin time "PTT", and chest x-ray. Electrocardiogram "ECG" was done for patients above 40 years old. All doses are based on ideal body weight.

In the operating room, after routine monitoring (ECG, Noninvasive blood pressure "NIBP", Pulse oximetry and End tidal $\mathrm{CO}_{2}$ "ET $\mathrm{CO}_{2}$ "), baseline vital signs were taken and $18 \mathrm{G}$ intravenous cannula was inserted to all patients.

Before induction of anesthesia, patients were randomly divided into two equal groups (40 patients each) by sealed envelopes:

Dexmedetomidine group (Group D): Non-opioid group received dexmedetomidine $(1 \mu \mathrm{g} / \mathrm{kg})$ over 10 minutes before induction of anesthesia followed by continuous infusion of $0.5 \mu \mathrm{g} / \mathrm{kg} / \mathrm{hr}$. till the end of surgery.

Fentanyl group (Group F): Opioid group received fentanyl $(1.0 \mu \mathrm{g} / \mathrm{kg})$ over 10 minutes before induction of anesthesia followed by continuous infusion of 0.4 $\mu \mathrm{g} / \mathrm{kg} / \mathrm{hr}$. till the end of surgery.

After preoxygenation with $100 \%$ oxygen for 5 minutes, anesthesia was induced with propofol $2 \mathrm{mg} / \mathrm{kg} \mathrm{IV}$ and atracurium 0.5 $\mathrm{mg} / \mathrm{kg}$ slowly IV followed by insertion of appropriate size endotracheal tube.

Anesthesia was maintained by volume-controlled ventilation (maintain ET co-around $35-38 \mathrm{mmHg}$ ), isoflurane $(1.15 \%)$ in $100 \%$ oxygen. Neuromuscular blockade will be maintained with atracurium $(0.15 \mathrm{mg} / \mathrm{kg})$ IV every 20 minutes.

Infusions of dexmedetomidine and fentanyl were maintained till the end of the surgery.

At the end of surgery, isoflurane and infusion of dexmedetomidine and fentanyl were discontinued.

Muscle relaxant was reversed by neostigmine $(0.05 \mathrm{mg} / \mathrm{kg})$ and atropine sulphate $(0.01-0.02 \mathrm{mg} / \mathrm{kg})$ IV followed by extubation after taking good regular tidal volume. Then the patient was transferred to the 
post anesthesia care unit (PACU). Duration of surgery and anesthesia were recorded.

\section{Statistical analysis}

SPSS version 17 program, Chicago USA, were used to enter data and statistical analysis. Data were presented as mean $\pm \mathrm{SD}$, number, and percent. Comparison between the two groups was performed using unpaired student s t-tests for parametric data, Chi-square

Table (1): Patients' demographic data.

\begin{tabular}{|l|c|c|c|c|}
\hline & \multirow{2}{*}{$\begin{array}{c}\text { Group D } \\
\text { Mean } \pm \text { SD } \\
\mathbf{N}(\%)\end{array}$} & $\begin{array}{c}\text { Group F } \\
\text { Mean } \pm \text { SD } \\
\mathbf{N}(\%)\end{array}$ & \multicolumn{2}{|c|}{ Tests } \\
\cline { 5 - 6 } & $43.1 \pm 10.6$ & $43.3 \pm 9.3$ & $\mathbf{X}^{2} / \mathbf{t}$ & P-value \\
\hline Age (years) & $28(70 \%) / 12(30 \%)$ & $27(67.5 \%) / 13(32.5 \%)$ & 0.09 & 0.928 \\
\hline $\begin{array}{l}\text { Gender } \\
(\text { Female } / \text { Male) }\end{array}$ & $27.2 \pm 3.9$ & $28.9 \pm 4.1$ & 1.9 & 0.928 \\
\hline BMI $\left(\mathbf{K g} / \mathbf{m}^{2}\right)$ & $34(85 \%) / 6(15 \%)$ & $31(77.5 \%) / 9(22.5 \%)$ & 0.738 & 0.390 \\
\hline $\begin{array}{l}\text { ASA physical status } \\
\text { (ASA I/ASA II) }\end{array}$ & $47.3 \pm 4.12$ & $48.2 \pm 3.9$ & 1.003 & 0.318 \\
\hline $\begin{array}{l}\text { Duration of surgery } \\
\text { (min.) }\end{array}$ & & & & 0.061 \\
\hline
\end{tabular}

There were no significant differences between the two groups regarding HR except after loading dose of the studied drugs, after intubation, after pneumoperitoneum, $15 \mathrm{~min}, 30 \mathrm{~min}, 45 \mathrm{~min}$, and 60 min after induction where it was lower in Group D than Group F (Table 2).

Table (2): Heart rate (beats/ min).

\begin{tabular}{|l|r|r|l|r|r|l|c|c|}
\hline \multirow{2}{*}{ Heart rate (beats/minute) } & \multicolumn{3}{c|}{ Group D } & \multicolumn{3}{c|}{ Group F } & \multicolumn{2}{c|}{ T-test } \\
\cline { 2 - 9 } \multicolumn{1}{|c|}{} & Mean & \pm & SD & Mean & \pm & SD & \multicolumn{1}{c|}{ T } & P-value \\
\hline Baseline & 84.1 & \pm & 3.89 & 82.73 & \pm & 3.67 & 1.620 & 0.109 \\
\hline After loading dose of the studied drugs & 73.6 & \pm & 3.18 & 73.4 & \pm & 8.88 & 0.134 & 0.893 \\
\hline After intubation & 88.47 & \pm & 14.28 & 100.37 & \pm & 13.29 & 3.858 & $<0.001^{* *}$ \\
\hline After pneumoperitoneum & 81.3 & \pm & 13.67 & 90.1 & \pm & 13.89 & 2.856 & $0.005^{*}$ \\
\hline 15 min. after induction & 79.4 & \pm & 12.75 & 87.47 & \pm & 9.13 & 3.255 & $0.002^{*}$ \\
\hline 30 min. after induction & 79.33 & \pm & 13.32 & 91.87 & \pm & 10.44 & 4.686 & $<0.001^{* *}$ \\
\hline 45 min, after induction & 85.73 & \pm & 13.85 & 91.37 & \pm & 10.21 & 2.073 & $0.042^{*}$ \\
\hline 60 min. after induction & 84.47 & \pm & 12.36 & 90.73 & \pm & 9.56 & 2.534 & $0.013^{*}$ \\
\hline Postop. 15 min. & 83.40 & \pm & 7.29 & 83.58 & \pm & 7.05 & 0.112 & 0.910 \\
\hline Postop.30 min. & 81.65 & \pm & 8.06 & 85.18 & \pm & 8.15 & 1.948 & 0.055 \\
\hline Postop.45 min. & 81.18 & \pm & 7.25 & 83.33 & \pm & 8.31 & 1.233 & 0.221 \\
\hline Postop.60 min. & 83.15 & \pm & 6.83 & 83.43 & \pm & 7.14 & 0.179 & 0.858 \\
\hline Postop.75 min. & 82.88 & \pm & 6.36 & 82.75 & \pm & 8.58 & 0.077 & 0.938 \\
\hline Postop.90 min. & 81.30 & \pm & 6.13 & 84.15 & \pm & 8.92 & 1.665 & 0.099 \\
\hline Postop.105 min. & 81.33 & \pm & 7.28 & 84.40 & \pm & 7.99 & 1.796 & 0.076 \\
\hline Postop.120 min. & 82.23 & \pm & 8.01 & 83.85 & \pm & 8.90 & 0.856 & 0.394 \\
\hline
\end{tabular}

There were no significant differences between the two groups regarding MAP except after loading dose of the studied drugs, after intubation, after pneumoperitoneum, $15 \mathrm{~min}$, and $60 \mathrm{~min}$ after induction where it was lower in Group D than Group F (Table 3). 
Table (3): Mean arterial pressure ( $\mathrm{mmHg})$.

\begin{tabular}{|l|r|l|l|r|l|l|l|c|}
\hline \multirow{2}{*}{ MAP (mmHg) } & \multicolumn{3}{c|}{ Group D } & \multicolumn{3}{c|}{ Group F } & \multicolumn{2}{c|}{ T-test } \\
\cline { 2 - 8 } & Mean & \pm & SD & Mean & \pm & SD & t & P-value \\
\hline Baseline & 92.23 & \pm & 8.45 & 91.17 & \pm & 7.46 & 0.595 & 0.553 \\
\hline After loading dose of the studied drugs & 82.47 & \pm & 7.99 & 89.40 & \pm & 8.18 & 3.833 & $<0.001^{* *}$ \\
\hline After intubation & 93.80 & \pm & 10.23 & 105.43 & \pm & 15.84 & 3.901 & $<0.001^{* *}$ \\
\hline After pneumoperitoneum & 85.97 & \pm & 11.40 & 93.80 & \pm & 12.74 & 2.897 & $0.005^{*}$ \\
\hline 15 min. after induction & 90.17 & \pm & 8.06 & 98.03 & \pm & 11.02 & 3.641 & $<0.001^{* *}$ \\
\hline 30 min. after induction & 90.33 & \pm & 7.86 & 95.27 & \pm & 12.22 & 2.150 & 0.035 \\
\hline 45 min. after induction & 91.50 & \pm & 7.32 & 94.47 & \pm & 10.51 & 1.467 & 0.146 \\
\hline 60 min. after induction & 89.00 & \pm & 4.38 & 94.70 & \pm & 11.09 & 3.023 & $0.003^{*}$ \\
\hline Postop. 15 min. & 100.40 & \pm & 5.97 & 100.20 & \pm & 6.53 & 0.143 & 0.886 \\
\hline Postop.30 min. & 99.93 & \pm & 5.43 & 100.68 & \pm & 5.43 & 0.618 & 0.538 \\
\hline Postop.45 min. & 99.55 & \pm & 6.86 & 100.70 & \pm & 5.55 & 0.824 & 0.412 \\
\hline Postop.60 min. & 98.33 & \pm & 5.72 & 100.93 & \pm & 6.01 & 1.982 & 0.051 \\
\hline Postop.75 min. & 99.50 & \pm & 6.44 & 100.70 & \pm & 5.48 & 0.898 & 0.372 \\
\hline Postop.90 min. & 100.48 & \pm & 6.70 & 100.25 & \pm & 5.67 & 0.166 & 0.868 \\
\hline Postop.105 min. & 99.68 & \pm & 6.04 & 100.30 & \pm & 5.81 & 0.468 & 0.641 \\
\hline Postop.120 min. & 100.48 & \pm & 5.68 & 100.88 & \pm & 5.82 & 0.311 & 0.756 \\
\hline
\end{tabular}

There were no significant differences regarding side effects between two groups except nausea and ondasterone use where they were significantly lower in Group D than Group F (Table 4).

Table (4): Side effects.

\begin{tabular}{|l|c|c|c|c|}
\hline \multirow{2}{*}{ Side effect } & Group D & Group F & \multicolumn{2}{|c|}{ Chi-square } \\
\cline { 4 - 5 } & $\mathbf{N}(\%)$ & $\mathbf{N}(\%)$ & $X^{2}$ & P-value \\
\hline Nausea & $5(12.5)$ & $13(32.5)$ & 4.588 & $0.032^{*}$ \\
\hline Vomiting & $1(2.5)$ & $5(12.5)$ & 2.883 & 0.090 \\
\hline Hypotension & $0(0)$ & $3(7.5)$ & 3.117 & 0.077 \\
\hline Bradycardia & $2(5)$ & $1(2.5)$ & 0.346 & 0.556 \\
\hline Ondasterone use & $0(0)$ & $6(15)$ & 6.486 & $0.011^{*}$ \\
\hline
\end{tabular}

Stay time at PACU is longer in group D than group $\mathrm{F}$ which is statically significant.

There was no statistically significant difference between both groups regarding discharge time from Hospital.

\section{DISCUSSION}

Pneumoperitoneum causes increase in systemic vascular resistance, mean arterial pressure, cardiac filling pressure and decrease in cardiac index. The $\mathrm{CO}_{2}$ insufflation results in its peritoneal absorption producing hypercarbia, which stimulates sympathetic nervous system and thus increases BP, HR and the risk of arrhythmia. Hypercapnia may cause a decrease in myocardial contractility and lowers arrhythmia threshold ${ }^{(9)}$.

In the current study there were no significant differences between the two groups regarding HR and MAP except after loading dose of the studied drugs, after intubation, after pneumoperitoneum, $15 \mathrm{~min}, 30 \mathrm{~min}, 45$ $\mathrm{min}$, and $60 \mathrm{~min}$ after induction where it was lower in dexmedetomidine group than fentanyl group.

Biccard et al. (10) reviewed the analgesic treatment after laparoscopic cholecystectomy, were consistent with our study results which showed a significant decrease in HR and MAP in dexmedetomidine group than fentanyl group.

Dexmedetomidine, being a highly selective $\alpha 2$ agonist, is sympatholytic and also has hemodynamic stability property. It leads to dose-dependent decrease in heart rate and blood pressure. This is due to decrease in central stimulation of parasympathetic outflow and inhibition of sympathetic outflow from the brainstem- the locus coeruleus ${ }^{(11)}$.

The present study showed that there were no significant differences between two groups regarding blood glucose level.

Akhtar et al. ${ }^{(12)}$ matched with our results of blood glucose concentrations while making a clinical implications of perioperative 
glucose regulation and control during laparoscopic surgery.

Gupta et al. ${ }^{(13)}$ found that increasing in blood glucose concentration was more pronounced in fentanyl group than in dexmedetomidine group during a clinical study of blood glucose estimation as an indirect assessment of modulation of neuroendocrine stress response by dexmedetomidine versus fentanyl premedication during laparoscopic cholecystectomy.

Increased circulating concentrations of catecholamines, glucagons, and cortisol can evoke the changes in carbohydrate metabolism, occurring immediately after trauma. The characteristic metabolic effect of cortisol is to decrease the rate at which insulin activates the glucose uptake system; hence, surgical stress led to greater activation of neuroendocrine response and hepatic gluconeogenesis under perioperative conditions ${ }^{(14)}$.

This study demonstrated that there were significant differences between two groups regarding VAS scores at 20 minutes, 60 minutes and 6 hours postoperatively where it was lower in dexmedetomidine group than fentanyl group. The duration of postoperative analgesia was significantly higher in dexmedetomidine group compared to fentanyl group. There was more delay in need for first dose of rescue analgesia in dexmedetomidine group than fentanyl group.

Kataria et al. (15) who studied the efficacy of dexmedetomidine and fentanyl on pressor response and pneumoperitoneum in laparoscopic cholecystectomy showed similar results in VAS score as the current study in postoperative period.

In the other hand Choi et al. ${ }^{(16)}$ did a comparison of an intraoperative infusion of dexmedetomidine, fentanyl, and remifentanil on perioperative hemodynamics, sedation quality, and postoperative pain control in laparoscopic total hysterectomy and observed that VAS scores of postoperative pain were not significantly different among dexmedetomidine, fentanyl and remifentanil groups.

In the present study, there were no significant differences regarding side effects between two groups such as hypotension and bradycardia. Nausea and ondasterone use were significantly lower in dexmedetomidine group than fentanyl group.

Feld $\boldsymbol{e t}$ al. ${ }^{(17)}$ who compare between fentanyl and dexmedetomidine combined with desflurane for laparoscopic bariatric surgery came in agreement with this study.

Dexmedetomidine can lead to cardiovascular depression, causing bradycardia and hypotension. Bradycardia is due to activation of alpha-2-adrenoceptors, imidazoline-preferring receptors or both in the ventrolateral medulla (18). However, dexmedetomidine useful in blunting the increase in systolic BP perioperatively, even though no increase the incidence of hypotension or bradycardia was seen ${ }^{(\mathbf{1 9})}$.

In the present study, stay time at PACU is longer in dexmedetomidine group than fentanyl group which is statically significant.

Bakan et al. ${ }^{(20)}$ studied opioid-free total intravenous anesthesia with propofol, dexmedetomidine and lidocaine infusions for laparoscopic cholecystectomy matched with this results as regard PACU discharge time.

Also Patel et al. ${ }^{(21)}$ while studying the effect of intravenous infusion of dexmedetomidine on perioperative hemodynamic changes and postoperative recovery in laparoscopic surgery found that postoperatively dexmedetomidine showed significant increase in PACU discharge time for two hours than fentanyl.

Otherwise, Vaswani et al. ${ }^{(22)}$ showed the effect of Dexmedetomidine Vs. Fentanyl on hemodynamic response in patients undergoing elective laparoscopic surgery and noticed that there were no statically difference between both groups regarding PACU discharge time.

Dexmedetomidine is increasingly being used as a sedative for Monitored Anesthesia Care (MAC) because of its cooperative sedation, anxiolytic and lack of respiratory depression effect ${ }^{(22)}$.

\section{CONCLUSION}

This study concluded that dexmedetomidine is better than fentanyl for patients who undergo elective laparoscopic cholecystectomy due to perioperative maintaining of hemodynamic stability, decrease dosages of postoperative analgesics, prolong the duration of postoperative analgesia and decrease postoperative nausea and vomiting. 


\section{REFERENCES}

1. Park JI, Kim KH, Lee SG (2015): Laparoscopic living donor hepatectomy: a review of current status. J Hepatobiliary Pancreat Sci., 22:779-88.

2. Awad H, Walker CM, Shaikh M, Dimitrova GT, Abaza R, O'Hara J (2012): Anesthetic considerations for robotic prostatectomy: A review of the literature. J Clin Anesth., 24:494-504.

3. Chodakiewitz YG, Bicalho GV, Chodakiewitz JW (2013): Multi-target neurostimulation for adequate long-term relief of neuropathic and nociceptive chronic pain components. Surgical neurology international, 4(3), S170.

4. Holtmann G, Gschossmann J, Mayr P, Talley NJ (2002): A randomized placebocontrolled trial of simethicone and cisapride for the treatment of patients with functional dyspepsia. Alimentary pharmacology \& therapeutics, 16(9):1641-48.

5. Gschossmann JM, Mayer EA, Miller JC, Raybould HE (2002): Subdiaphragmatic vagal afferent innervation in activation of an opioidergic antinociceptive system in response to colorectal distension in rats. Neurogastroenterology \& Motility, 14(4): 403-8.

6. Angst MS, Clark JD (2006): Opioidinduced hyperalgesia: A qualitative systematic review. Anesthesiology, 104:570-87.

7. Cepeda MS, Farrar JT, Baumgarten M, Boston R, Carr DB, Strom BL (2003): Side effects of opioids during short-term administration: Effect of age, gender, and race. Clin Pharmacol Ther., 74:102-12.

8. Feld JM, Laurito CE, Beckerman M, Vincent J, Hoffman WE (2003): Nonopioid analgesia improves pain relief and decreases sedation after gastric bypass surgery. Can J Anaesth., 50:336-41.

9. Russo A, Marana E, Viviani D, Polidori L, Colicci S, Mettimano M, Di Stasio E (2009): Diastolic function: the influence of pneumoperitoneum and Trendelenburg positioning during laparoscopic hysterectomy. European Journal of Anaesthesiology (EJA), 26(11): 923-27.

10. Biccard BM, Goga S, De Beurs, J (2008): Dexmedetomidine and cardiac protection for non-cardiac surgery: A meta-analysis of randomised controlled trials. Anaesthesia, 63(1): 4-14.

11. Bajwa SJ, Kulshrestha A (2013): Dexmedetomidine: an adjuvant making large inroads into clinical practice. Annals of medical and health sciences research, 3(4): 475-83.

12. Akhtar S, Barash PG, Inzucchi SE (2010): Scientific principles and clinical implications of perioperative glucose regulation and control. Anesthesia \& Analgesia, 110(2):478-97.

13. Gupta K, Maggo A, Jain M, Gupta PK, Rastogi B, Singhal AB (2013): Blood glucose estimation as an indirect assessment of modulation of neuroendocrine stress response by dexmedetomidine versus fentanyl premedication during laparoscopic cholecystectomy: A clinical study. Anesthesia, essays and researches, 7(1):34.

14. Gutierrez-Blanco E, Victoria-Mora JM, Ibancovichi-Camarillo JA, Sauri-Arceo CH, Bolio-González ME, AcevedoArcique CM, Steagall PV (2013): Evaluation of the isoflurane-sparing effects of fentanyl, lidocaine, ketamine, dexmedetomidine, or the combination lidocaine ketamine dexmedetomidine during ovariohysterectomy in dogs. Veterinary anaesthesia and analgesia, 40(6):599-609.

15. Kataria AP, Attri JP, Kashyap R, Mahajan L (2016): Efficacy of dexmedetomidine and fentanyl on pressor response and pneumoperitoneum in laparoscopic cholecystectomy. Anesthesia, essays and researches, 10(3): 446.

16. Choi JW, Joo JD, Kim DW, In JH, Kwon SY, Seo K, Jung HS (2016): Comparison of an intraoperative infusion of dexmedetomidine, fentanyl, and remifentanil on perioperative hemodynamics, sedation quality, and postoperative pain control. Journal of Korean medical science, 31(9): 1485-90.

17. Feld J, Hoffman WE, Paisansathan C, Park H, Ananda RC (2007): Autonomic activity during dexmedetomidine or fentanyl infusion with desflurane anesthesia. Journal of clinical anesthesia, 19(1): 30-36.

18. Vora KS, Baranda U, Shah VR, Modi M, Parikh GP, Butala BP (2015): The 
effects of dexmedetomidine on attenuation of hemodynamic changes and their effects as adjuvant in anesthesia during laparoscopic surgeries. Saudi journal of anaesthesia, 9(4): 386.

19. Batra A, Verma $R$, Bhatia $V \mathrm{~K}$, Chandra G, Bhushan S (2017): Dexmedetomidine as an anesthetic adjuvant in intracranial surgery. Anesthesia, essays and researches, 11(2): 309.

20. Bakan M, Umutoglu T, Topuz, U, Uysal H, Bayram M, Kadioglu H, Salihoglu Z (2015): Opioid-free total intravenous anesthesia with propofol, dexmedetomidine and lidocaine infusions for laparoscopic cholecystectomy: a prospective, randomized, double-blinded study. Revista brasileira de anestesiologia, 65(3): 191-99.
21. Patel CR, Engineer SR, Shah BJ, Madhu S (2012): Effect of intravenous infusion of dexmedetomidine on perioperative haemodynamic changes and postoperative recovery: A study with entropy analysis. Indian journal of anaesthesia, 56(6): 542.

22. Vaswani JP, Debata D, Vyas V, Pattil S (2017): Comparative Study of the Effect of Dexmedetomidine Vs. Fentanyl on Haemodynamic Response in Patients Undergoing Elective Laparoscopic Surgery. Journal of clinical and diagnostic research: JCDR., 11(9):4. 